\title{
Numerical investigation of natural convection in an inclined wavy solar collector containing a nanofluid
}

\author{
S Kadri*, K Djermane', E Bourbaba', M Elmir², R Mehdaoui² \\ 1. LPDS Laboratory, Exact Sciences Faculty, TAHRI Mohamed \\ University, Bechar, Algeria \\ 2. ENERGARID Laboratory, Technology Faculty, TAHRI Mohamed \\ University, Bechar, Algeria
}

\begin{abstract}
The present paper gives a numerical study of natural convection heat transfer inside the inclined wavy solar collectors containing nanofluid in Bechar region. Bechar is located in the southwest of Algeria and belongs to the semi-arid zone. The solar deposit of this city corresponds to an angle of inclination of $\alpha=37$.The collector has a wavy absorber and cover. The inclined corrugated walls are maintained at constant temperature but different values. The vertical walls are assumed to be adiabatic. The nanofluid used is $\mathrm{Al}_{2} \mathrm{O}_{3}$-water. This problem consists in solving the system of equations containing: mass conservation, Navier Stokes and energy with adapted simplified hypotheses. Transport equations are solved numerically by finite element method. Governing parameters are taken as Rayleigh number (from $10^{5}$ to $4 \times 10^{6}$ ), volume fraction (from 0 to $10 \%$ ), amplitude of wavy cover (from 0 to 0.2) and wave of number (from 1.5 to 3.5). Results are presented by stream function and overage Nusselt numbers.
\end{abstract}

\section{INTRODUCTION}

The solar collectors which convert solar radiation to thermal energy then transfer it towards the carrying fluid has several practical and industrial applications, including electrical production, energy systems heating and cooling [1-3]. The solar collectors are designed usually as (flat) shallow enclosures but their absorbers can be different geometry such as wavy or corrugated. Also, they mounted with an inclination angle to receive more solar radiation [4]. However, the flat-plat collector has relatively low energy efficiency and low outlet temperatures. Recently, several studies have been carried out on the flat plate solar collector solar collector to overcome these disadvantages $[2,5]$, in addition to these classical studies or methods, which are used to increase the thermal efficiency of this kind of solar collector, one of the latest effective method is to replace the conventional working fluid by other fluids, which having higher thermal properties.

Recently researchers have become interested in the use of nanofluids in collectors [6]. A nanofluid is a fluid which contains nanometer-sized solid particles. Nanofluids were introduced by Choi [7] and they have been proven to provide efficient heat transfer compared to conventional fluids [8]. Usually, the nanoparticles that are used in nanofluid are made of metals, carbides, carbon nanotubes or oxides [9-13]. 
The problem of the natural convection in a cavity differentially heated is studied numerically by several researchers [14-20]. Marina S. Astanina et al [21] studied numerically laminar natural convection in a square cavity having two centered adherent porous blocks filled with an alumina/water nanofluid under the effect of horizontal temperature gradient. The obtained results revealed the heat transfer enhancement at the hot wall with the Darcy number, while a growth of the porous layers size reduces the heat transfer rate at this hot wall. The behavior of the average Nusselt number at the right cold wall is opposite. Sheikholeslami et al. [22, 23] was examined natural convection heat transfer in a porous medium with nanofluid. They found that the improvement of the heat transfer coefficient is related to the increase of nanoparticles volume concentration.

Various studies have treated solar collectors with a corrugated and wavy absorber filled with a nanofluid. Yasin Varol et al. [24] presented a comparative numerical study on natural convection in inclined wavy and flat-plate solar collectors. It has observed that flow and thermal fields are affected by the shape of enclosure and heat transfer rate increases in the case of wavy enclosure than that of flat enclosure. R. Nasrin et al. [25] have analyzed numerically the effect of aspect ratio on convective flow inside a solar collector having the flat-plate cover and sinusoidal wavy absorber. The results showed that the performance of the collector can be improved by using the largest Aspect ratio of solar collector $(\mathrm{Ar}=\mathrm{L} / \mathrm{H})$. The result of this study expresses a good agreement with the theoretical result available in the literature. M.M. Rahman et al. [26] has been studied a corrugated bottom triangular solar collector introducing water based nanofluids inside the enclosure. It has been found that both Grashof number and solid volume fraction have significant influence on streamlines and isotherms in the enclosure. It is also found that heat transfer increased by $24.28 \%$ from the heated surface as volume fraction $\varphi$ increases from $0 \%$ to $10 \%$ at $\mathrm{Gr}=106$ and $\tau=1$ for copper water nanofluid. Nasrin et al. [27] have showed a numerical study of forced convection heat transfer through a flat plate solar collector, the geometry is tested for $2 \mathrm{D}$ case, then $3 \mathrm{D}$, where water and $\mathrm{Cu}-\mathrm{H}_{2} \mathrm{O}$ nanofluid are used as a working fluid. The results obtained show that $3 \mathrm{D}$ simulation is more efficient than $2 \mathrm{D}$, and the increase of nanoparticles volume concentration gives an improvement in heat transfer rate reach $17 \%$ and about $8 \%$ for thermal efficiency of solar collector. Ammar Maouassi et al. [28] illustrated with numerical study of nanofluid (water- $\mathrm{SiO}_{2}$ ) to stimulate solar flat plate collector efficiency with heat transfer modification properties. They concluded that heat transfer increases with increasing both nanoparticles concentration and Reynolds number.

In this paper, we investigate numerically the heat transfer of nanofluid (water- $\mathrm{Al}_{2} \mathrm{O}_{3}$ ) flows through an inclined wavy solar collector. We examined the effect of nanoparticles volume fraction, the Rayleigh number, amplitude of wavy cover and number of wave. The objective of this article is to introduce the convective heat transfer and the flux intensity of a corrugated solar collector used to exploit solar energy in our semi-arid region. 


\section{MATHEMATICAL MODEL}

The inclined wavy solar collector geometry of the physical problem considered, and boundary conditions are shown in Figure 1. The nanofluid used in the collector is water-Al2O3 and is assumed to be Newtonian, isotropic and homogeneous. The flow is laminar, transient, incompressible and two-dimensional. The thermophysical properties of the nanofluid are assumed to be constant. The fluid phase and that of the nanoparticles are in a state of thermal equilibrium and flow with the same velocity. The solar collector is composed of a wavy cover plate on the top surface and a wavy absorber plate on the bottom. This corrugation is traced by the second-order Bezier curve. Both plates are maintained at fixed and determined temperatures. The length and height of the collector are $\mathrm{L}$ and $\mathrm{H}$ respectively. The density of the nanofluid is approximated by the Boussinesq model.

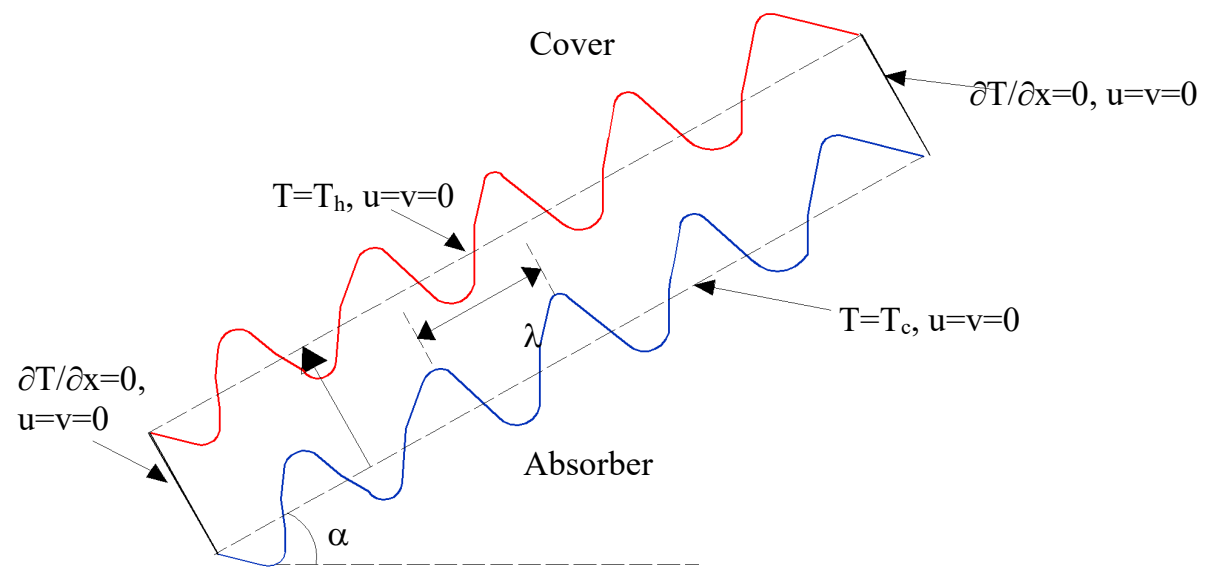

Figure 1: Physical model and boundary conditions.

The non-dimensional version of the governing system of transport equations are as follow:

$$
\begin{gathered}
\frac{\partial u}{\partial x}+\frac{\partial v}{\partial y}=0 \\
\frac{\partial u}{\partial t}+u \frac{\partial u}{\partial x}+v \frac{\partial u}{\partial y}=-\frac{1}{\rho_{n f}} \frac{\partial P}{\partial x}+\frac{\mu_{e f f}}{\rho_{n f}}\left(\frac{\partial^{2} u}{\partial x^{2}}+\frac{\partial^{2} u}{\partial y^{2}}\right)+\beta_{n f}\left(T-T_{f}\right) g \sin (\alpha)
\end{gathered}
$$




$$
\begin{gathered}
\frac{\partial v}{\partial t}+u \frac{\partial v}{\partial x}+v \frac{\partial v}{\partial y}=-\frac{1}{\rho_{n f}} \frac{\partial P}{\partial y}+\frac{\mu_{e f f}}{\rho_{n f}}\left(\frac{\partial^{2} v}{\partial x^{2}}+\frac{\partial^{2} v}{\partial y^{2}}\right)+\beta_{n f}\left(T-T_{f}\right) g \cos (\alpha) \\
\frac{\partial T}{\partial t}+u \frac{\partial T}{\partial x}+v \frac{\partial T}{\partial y}=\alpha_{n f}\left(\frac{\partial^{2} T}{\partial x^{2}}+\frac{\partial^{2} T}{\partial y^{2}}\right) \\
\frac{\partial^{2} \psi}{\partial x^{2}}+\frac{\partial^{2} \psi}{\partial y^{2}}=\frac{\partial u}{\partial y}-\frac{\partial v}{\partial x}
\end{gathered}
$$

The thermal diffusivity, the effective density, the heat capacitance and the thermal expansion coefficient of nanofluid are given by:

$$
\begin{gathered}
\alpha_{n f}=\frac{K_{n f}}{\left(\rho C_{p}\right)_{n f}} \\
\rho_{n f}=(1-\phi) \rho_{f}+\phi \rho_{s} \\
\left(\rho C_{p}\right)_{n f}=(1-\phi)\left(\rho C_{p}\right)_{f}+\phi\left(\rho C_{p}\right)_{s} \\
(\beta)_{n f}=(1-\phi)(\beta)_{f}+\phi(\beta)_{s}
\end{gathered}
$$

The original closed-type impeller wheel is shown in Figure 1 a), and the modified opentype impeller wheel calculated according to the methodology above is shown in Figure $1 \mathrm{~b}$ ).

$$
\begin{gathered}
\phi\left(\frac{k_{s}-k_{\text {eff }}}{k_{s}-2 k_{\text {eff }}}\right)+(1-\phi)\left(\frac{k_{f}-k_{\text {eff }}}{k_{f}+2 k_{\text {eff }}}\right)=0 \\
\mu_{\text {eff }}=\frac{\mu_{f}}{(1-\phi)^{2.5}}
\end{gathered}
$$

Based upon the previous assumptions and introducing the following dimensionless variables,

$$
\left(x^{*}, y^{*}\right)=\frac{(x, y)}{H},\left(u^{*}, v^{*}\right)=\frac{H(u, v)}{\alpha_{f}}, T^{*}=\frac{\left(T-T_{c}\right)}{\left(T_{h}-T_{c}\right)}, P^{*}=\frac{P H^{2}}{\rho_{f} \alpha_{f}^{2}},
$$


The governing equations for the problem in dimensionless form are as follows:

$$
\begin{aligned}
& \frac{\partial u^{*}}{\partial x^{*}}+\frac{\partial v^{*}}{\partial y^{*}}=0 \\
& \left(1-\phi+\phi R_{\rho}\right)\left(\frac{\partial u^{*}}{\partial t^{*}}+u^{*} \frac{\partial u^{*}}{\partial x^{*}}+v \frac{\partial u^{*}}{\partial y^{*}}\right)=-\frac{\partial P^{*}}{\partial x^{*}}+\frac{\operatorname{Pr}}{(1-\phi)^{2.5}}\left(\frac{\partial^{2} u^{*}}{\partial x^{* 2}}+\frac{\partial^{2} u^{*}}{\partial y^{* 2}}\right) \\
& +\operatorname{Pr} R a \sin (\varphi)\left(1-\phi+R_{\rho} R_{\beta} \phi\right) T^{*} \\
& \left(1-\phi+\phi R_{\rho}\right)\left(\frac{\partial u^{*}}{\partial t^{*}}+u^{*} \frac{\partial u^{*}}{\partial x^{*}}+v^{*} \frac{\partial u^{*}}{\partial y^{*}}\right)=-\frac{\partial P^{*}}{\partial x^{*}}+\frac{\operatorname{Pr}}{(1-\phi)^{2.5}}\left(\frac{\partial^{2} u^{*}}{\partial x^{* 2}}+\frac{\partial^{2} u^{*}}{\partial y^{* 2}}\right) \\
& +\operatorname{Pr} R a \cos (\varphi)\left(1-\phi+R_{\rho} R_{\beta} \phi\right) T^{*} \\
& \frac{\partial T^{*}}{\partial t^{*}}+u^{*} \frac{\partial T^{*}}{\partial x^{*}}+v^{*} \frac{\partial T^{*}}{\partial y^{*}}=\left[\frac{K_{n f}}{K_{f}}\right]\left(\frac{1}{(1-\phi)+\phi R_{\rho} R_{C p}}\right)\left(\frac{\partial^{2} T^{*}}{\partial x^{* 2}+\frac{\partial^{2} T^{*}}{\partial y^{* 2}}}\right)
\end{aligned}
$$

Non-dimensional parameters can be given as:

$$
\operatorname{Pr}=\frac{\mu_{e f f}}{\rho_{f} \alpha_{f}^{2}}, \quad R a=\frac{\rho_{f} \beta_{f} H^{3} g \Delta T}{\mu_{f} \alpha_{f}}, \quad R_{\rho}=\frac{\rho_{s}}{\rho_{f}}, \quad R_{\beta}=\frac{\beta_{S}}{\beta_{f}}, \mathrm{R}_{\mathrm{k}}=\frac{K_{s}}{K_{f}}, \mathrm{R}_{\mathrm{C}_{\mathrm{p}}}=\frac{C_{p s}}{C_{p f}}
$$

The heat transfer is characterized by the flux ratio between nanofluid and fluid. The average flux ratio at the hot inclined corrugated wall is computed as follows:

$$
\frac{Q_{n f}}{Q_{f}}=-\int_{0}^{l} \frac{K_{n f}}{K_{f}}\left(\frac{\partial T^{*}}{\partial x^{*}} \cos \alpha+\frac{\partial T^{*}}{\partial y^{*}} \sin \alpha\right)
$$

Dimensionless boundary conditions for Eqns. (11)-(14) are as follows:

- $u^{*}=v^{*}=0$ and $T^{*}=1$ at wavy cover surface

- $u^{*}=v^{*}=0$ and $T^{*}=0$ at wavy absorber surface

- $u^{*}=v^{*}=0$ and $\partial T^{*} / \partial x^{*}=0$ at vertical walls 


\section{NUMERICAL METHOD AND VALIDATION}

The nonlinear governing partial differential equations, i.e., mass, momentum and energy conservation equations are transformed into a system of integral equations by using the Galerkin weighted residual method of finite-element formulation. The nonlinear algebraic equations so obtained are modified by imposition of boundary conditions. These modified nonlinear equations are transferred into linear algebraic equations with the help of Lagrange's method. Lastly, these linear equations are solved by applying Triangular factorization. In our work, several simulations are taken into account according to the amplitude values and the number of waves. The number of elements varies between 2048 to 9664 .

To ensure the accuracy of the available code, the numerical results were compared with similar works. Consequently, a more general case, in which the natural convection is present in a wavy solar collector subjected to solar irradiance in top wall, was used for comparison purpose. A comparison is made between results of the average Nusselt number obtained from this study with Nesrin published results [25] as shown in Figure 1. The numerical solutions (present work and Nesrin et al. [25]) are in good agreement.

\section{RESULTS AND DISCUSSION}

In this numerical analyze, the average Nusselt number and maximal stream function has been carried out for various values of physical parameters such as amplitude of wave A, number of wave $\lambda$, nanoparticles volume fraction and Rayleigh number with an Al2O3/water nanofluid in a solar collector. The effect of the heat transfer is studied using the following range of values are given Rayleigh number $(105 \leq \mathrm{Ra} \leq 4 \times 106)$, volume fraction of nanoparticles from $\varphi=0$ to $\varphi=10 \%$, amplitude of wavy cover $(0,0.025,0.05,0.1$ and 0.2$)$, number of wave from $\lambda=1$ to $\lambda=3.5$, inclination angle of cavity $\alpha=37^{\circ}$ and Prandtl number $\mathrm{Pr}=7$. The thermophysical properties of the water base fluid and $\mathrm{A} 12 \mathrm{O} 3$ nanoparticles are shown in Table 1.

Table 1: Thermophysical properties of $\mathrm{Al}_{2} \mathrm{O}_{3}$-water [32]

\begin{tabular}{lll}
\hline Thermophysical properties & $\mathbf{A l}_{2} \mathbf{O}_{3}$ & Water \\
\hline$\rho\left(\mathrm{kg} \cdot \mathrm{m}^{-3}\right)$ & 3970 & 997.1 \\
$\mathrm{C}_{\mathrm{p}}(\mathrm{J} / \mathrm{kg} \cdot \mathrm{K})$ & 765 & 4179 \\
$\mathrm{~K}(\mathrm{~W} / \mathrm{m} \mathrm{K})$ & 40 & 0.6 \\
$\beta(1 / \mathrm{K})$ & $0.85 \times 10^{-5}$ & $21 \times 10^{-5}$ \\
\hline
\end{tabular}




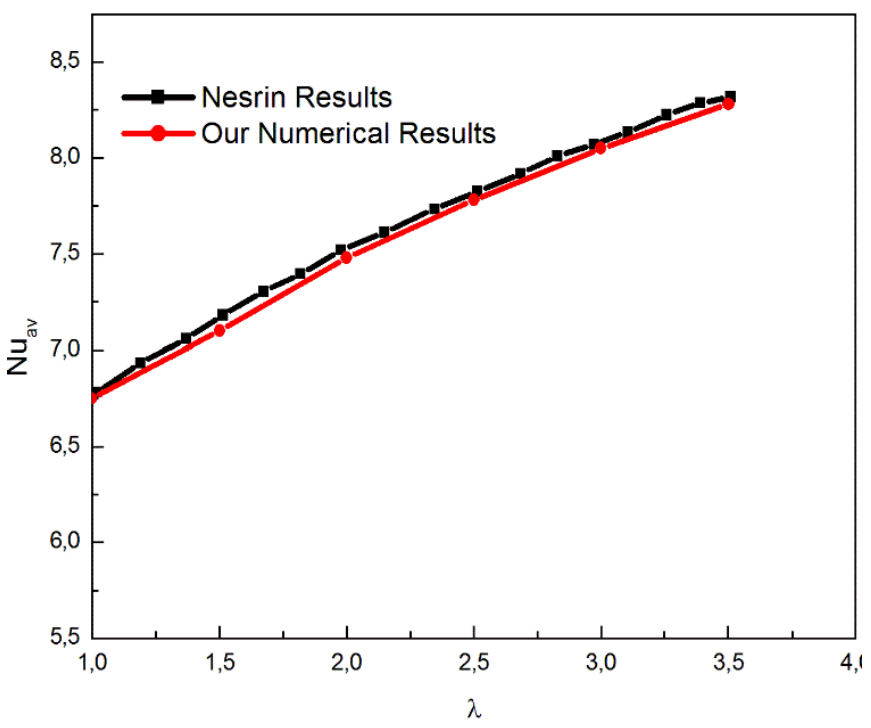

Figure 2: Comparison between present code and Nesrin results [25].

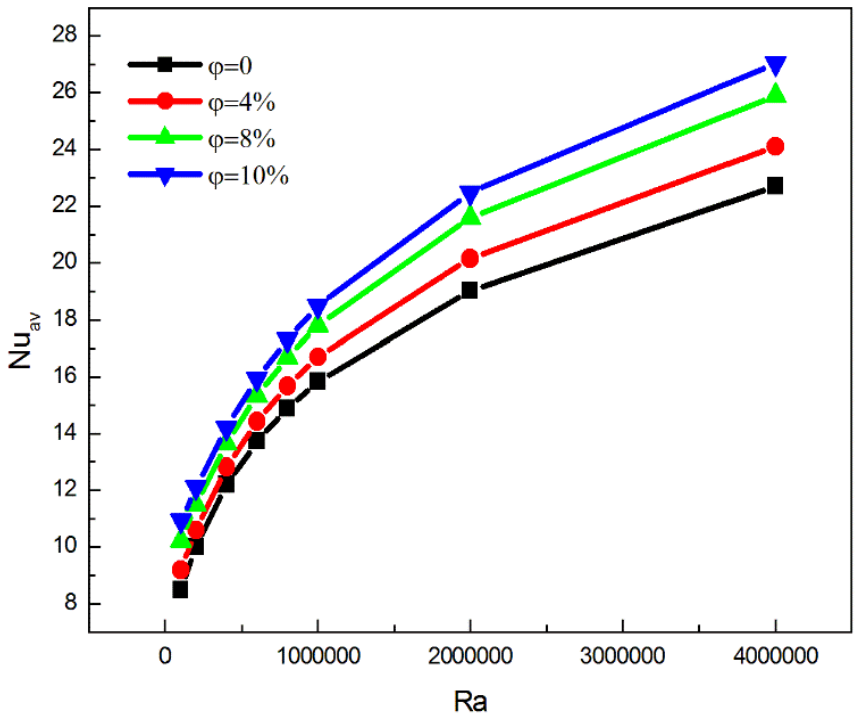

Figure 3: Variation of the average Nusselt number as a function of the Rayleigh number for different values of the nanoparticles volume fraction

The evolution of the average Nusselt number as a function of the Rayleigh number at different values of the volume fraction is illustrated in figure 3. The increase in Rayleigh number leads to an increase in the average Nusselt number, which means that the rate convection transfer is favored inside the solar collector. Also, the addition of nanoparticles improves the average Nusselt number compared to the base fluid (water). This improvement is justified by the large value of the thermal conductivity of the nanoparticles. 


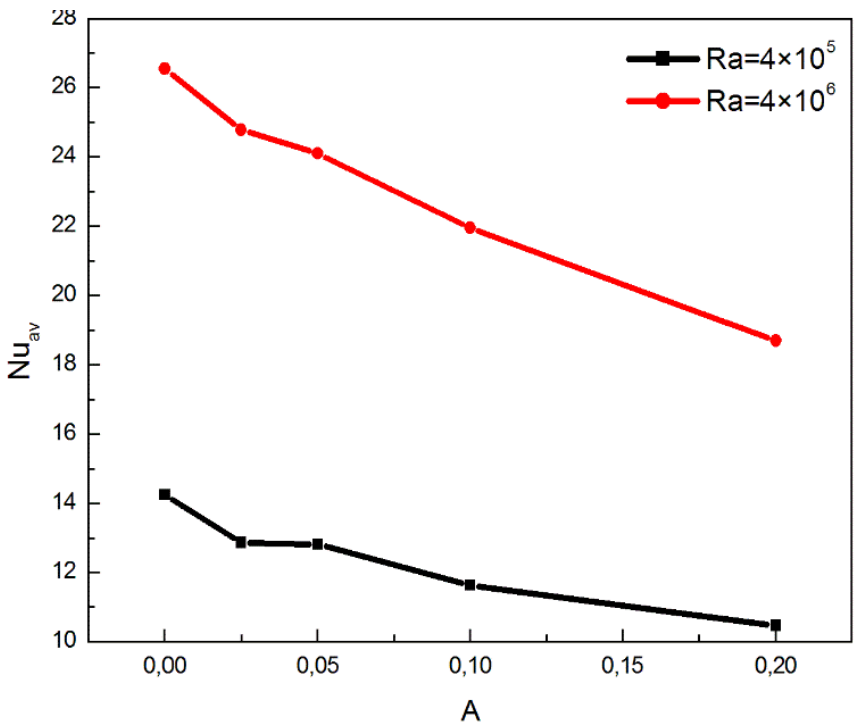

(a)

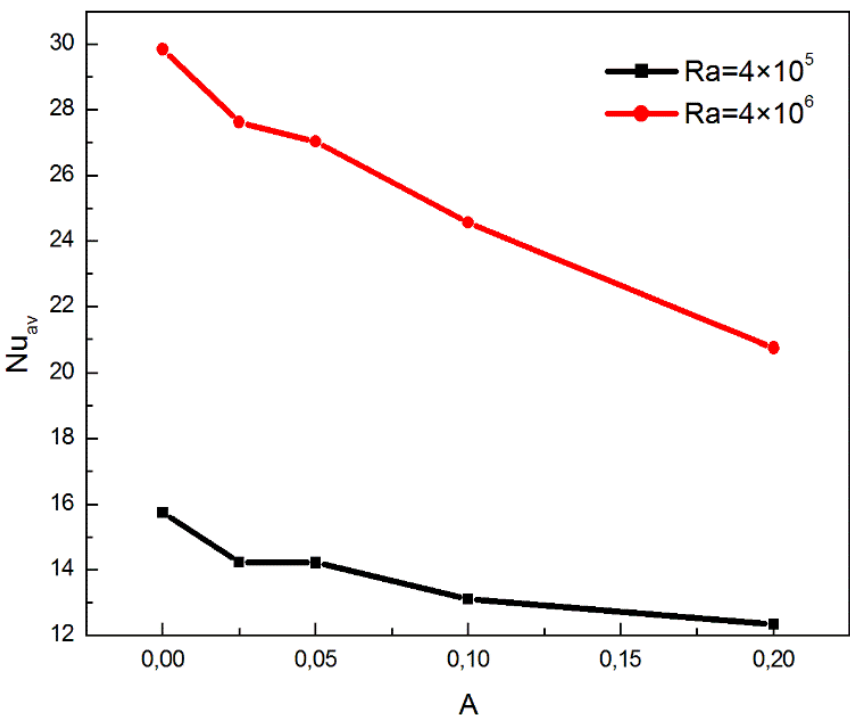

(b)

Figure 4: Variation of average Nusselt number depending on the wavy cover amplitude for two values of Rayleigh number for: (a) - $\varphi=0.04$ and (b) $-\varphi=0.1$.

Figure 4 shows the variation of Nusselt number as a function of the amplitude of the wavy cover for two values of Rayleigh number at $\varphi=0.04$ and $\varphi=0.1$. In figure (4.a), the average Nusselt number decreases with the increase in the amplitude of the wavy cover which means that the transfer rate by convection and the intensity of the flow decrease. The same remarks for figure (4.b) except that the average Nusselt number values get larger because of the increase in the volume fraction. 


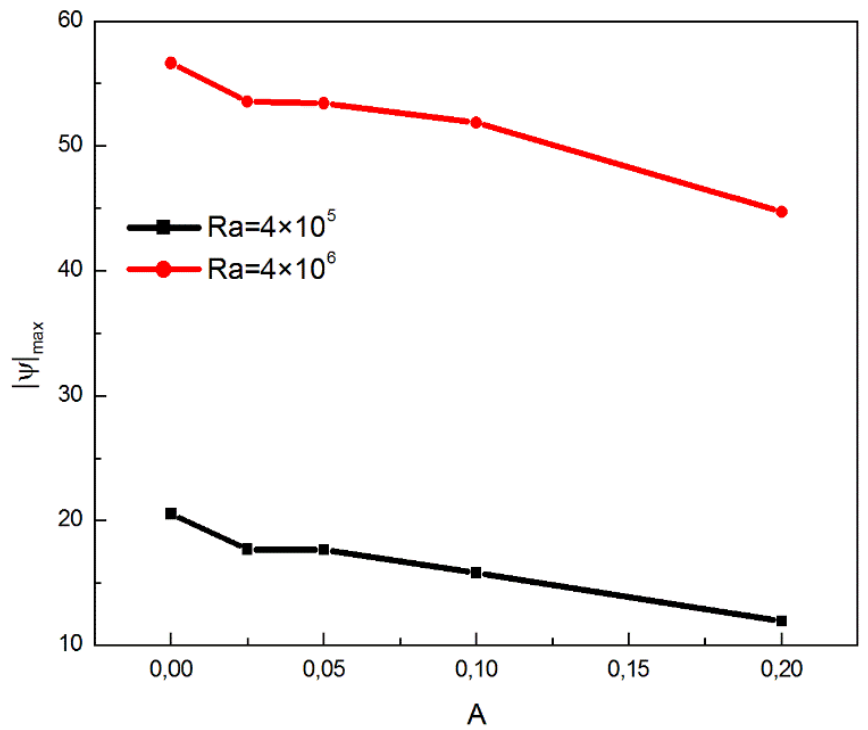

(a)

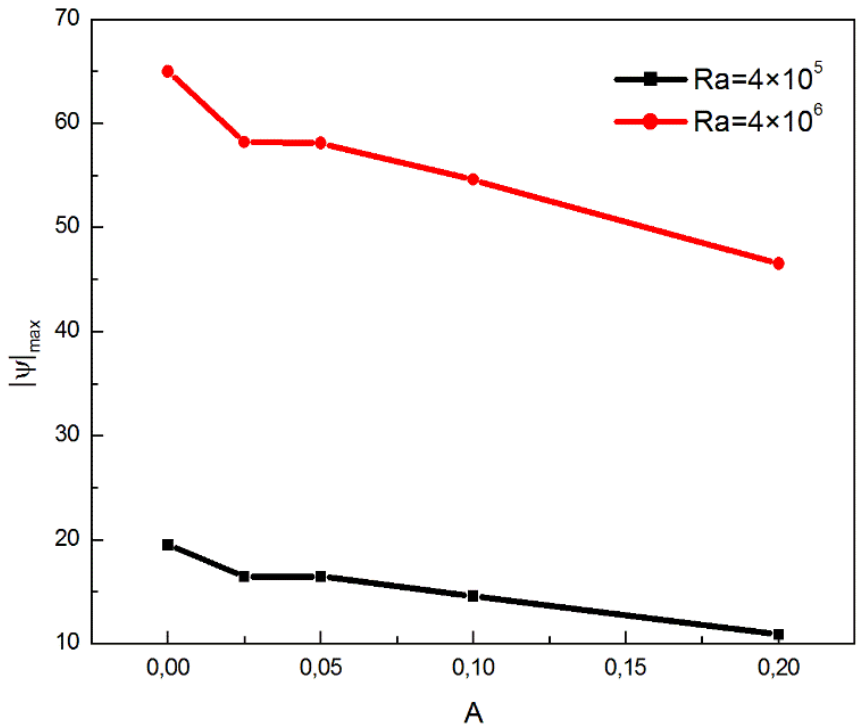

(b)

Figure 5: Variation of the maximum absolute value of the stream function depending on the wavy cover amplitude for two values of Rayleigh number for: (a) - $\varphi=0.04$ and $(b)-\varphi=0.1$.

Figure 5 presents the variation of the maximum stream function as a function of the amplitude of wavy cover for two Rayleigh number value at $\varphi=0.04$ and $\varphi=0.1$. The two figures confirm the previous observations. 


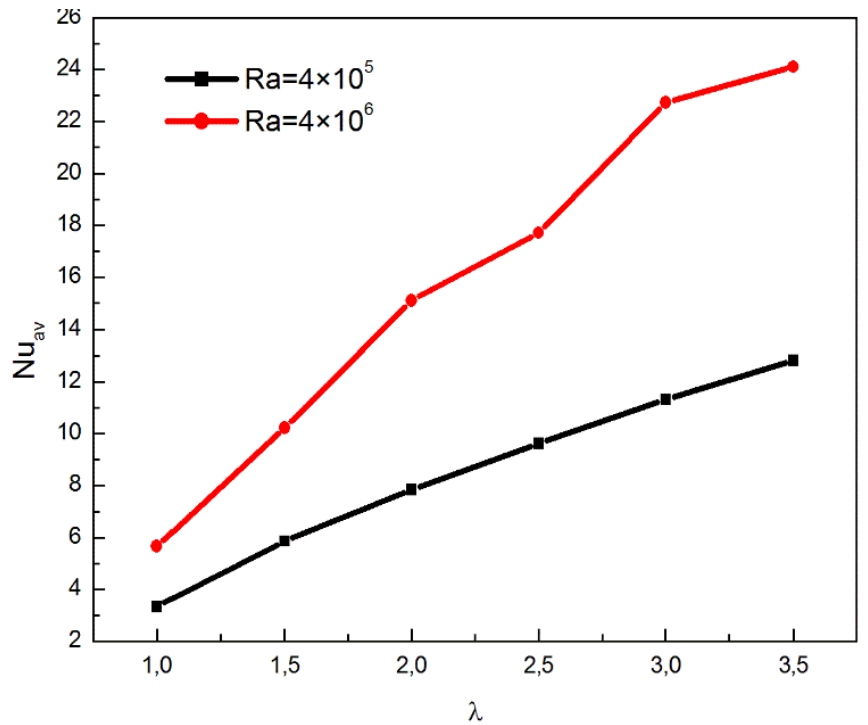

(a)

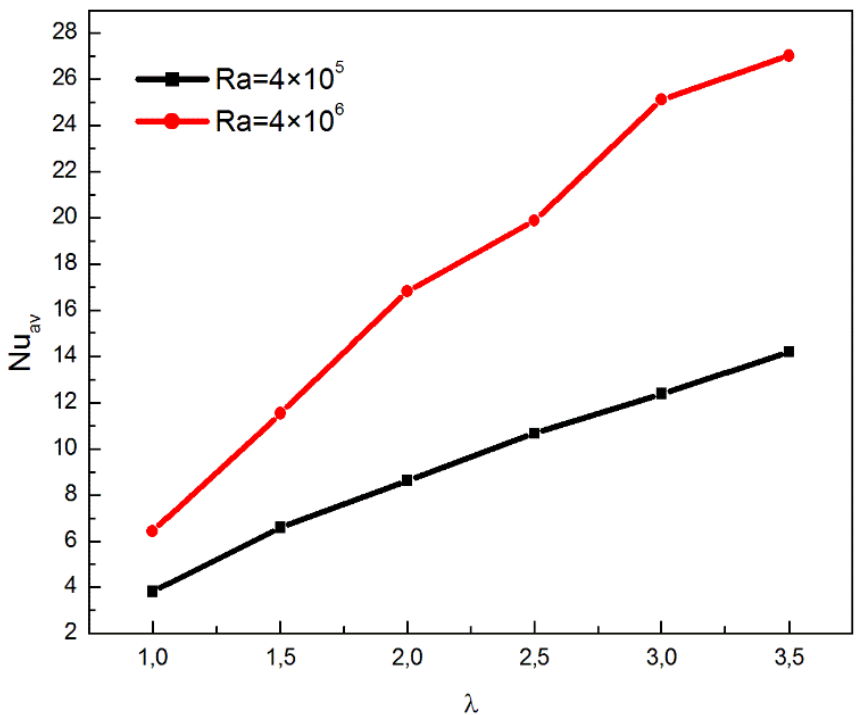

(b)

Figure 6: Variation of the average Nusselt number as a function of the waves number for two values of Rayleigh number for: (a) - $\varphi=0.04$ and (b) $\varphi=0.1$.

Figure 6 illustrates the effect of the number of waves on the average Nusselt number for two values of Rayleigh number at $\varphi=0.04$ and $\varphi=0.1$. For the both figures (6.a and 6.b), the average Nusselt number increases with the number of waves. At $\mathrm{Ra}=4 \times 105$ and for $\lambda=2.5$, $\mathrm{Nu}_{\mathrm{av}}=9.6268$ and it increases by a ratio of $27.7 \%$ for $\lambda=3.5$. For $\mathrm{Ra}=4 \times 106$, the ratio between $\mathrm{Nu}_{\mathrm{av}}(\lambda=2.5)$ and $\mathrm{Nu}_{\mathrm{av}}(\lambda=3.5)$ is $26.5 \%$. Therefore, the increase in the number of undulations leads to a dominance of the convective mode. 


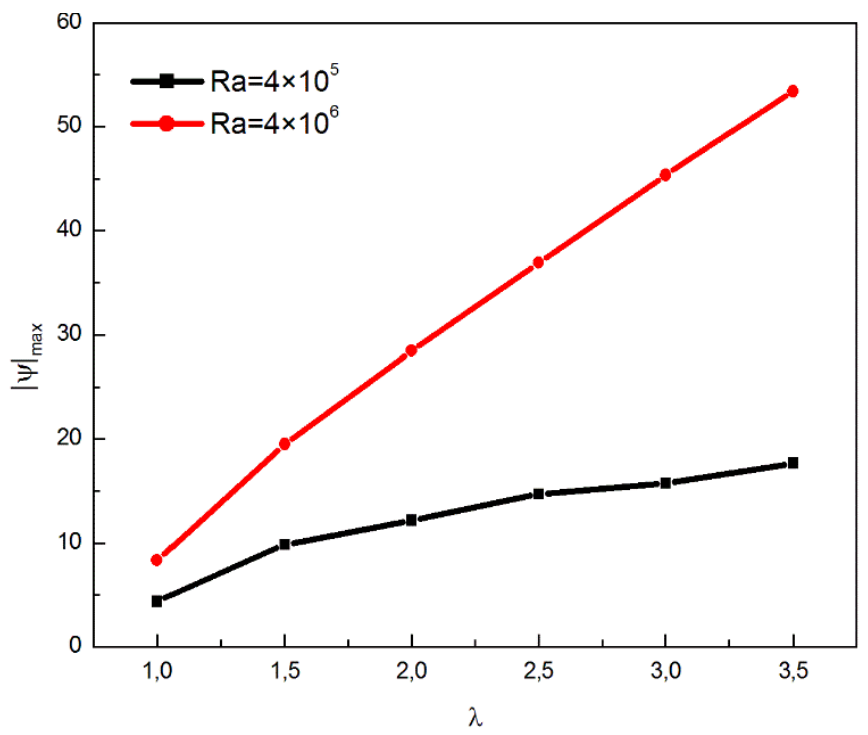

(a)

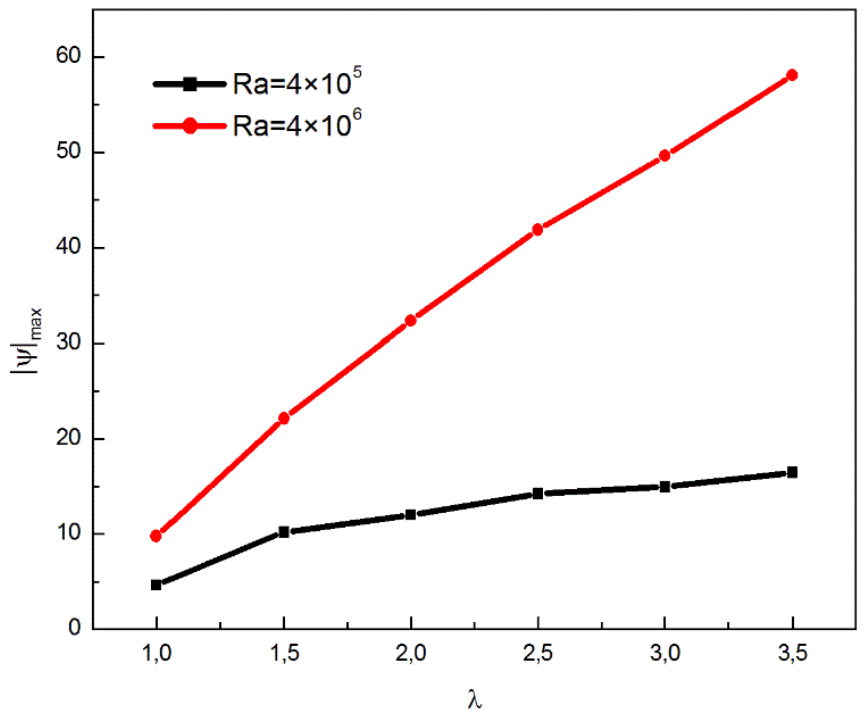

(b)

Figure 7: Variation of the maximum absolute value of the stream function depending on the waves number for two values of Rayleigh number to (a) - $\varphi=0.04$ and $(b)-\varphi=0.1$

Figures (7-a) and (7-b) represent the evolution of the maximum absolute value of the stream function depending on the waves number for two values of Rayleigh number for $\varphi=4 \%$ and $\varphi=10 \%$, respectively. The two curves indicate that $|\psi|_{\max }$ increase with increasing the cover wave number. This increase shows that the intensity of the flow and the force of circulation enhances with the waves number. This is owing to the increment in the viscosity forces. 


\section{CONCLUSIONS}

In this paper, the flow and heat transfer characteristics of $\mathrm{Al} 2 \mathrm{O} 3$ through a wavy solar collector, for Rayleigh number values from 105 to $4 \times 106$, amplitude of wavy cover from 0.025 to 0.2 , number of waves from 1 to 3.5 , with a wide range of volume concentration ( 0 to $10 \%$ ) are studied numerically. First, the presence of nanoparticles in the base fluid (pure water), increases significantly Nusselt number and maximum absolute value of the stream function, that is also proportional with the increase of Rayleigh number. Second, the amplitude of the waves decreases the Nusselt number and the maximum value of the current function. Third, the number of corrugations enhances the heat transfer by convection (increase in Nuav) and the intensity of the flow (increase in $|\psi| \max$ ). Finally, the Al2O3 nanoparticles with the highest wave amplitude and number of waves increase performance of heat transfer rate results in a good heat transfer between the energy systems compared to the base fluid (pure water) case.

\section{REFERENCES}

[1] Varola, H.F. Oztop, A comparative numerical study on natural convection in inclined wavy and flat-plate solar collectors, Building and Environment 43 (2008) 1535-1544.

[2] Rovense F., Amelio M., Ferraro V., Scornaienchi N.M. (2016). Analysis of a concentrating solar power tower operating with a closed joule Brayton cycle and thermal storage, International Journal of Heat and Technology, Vol.34, No.3, pp.485-490.

[3] Nasrin R., Alim M.A. (2015). Thermal performance of nanofluid filled solar flat plate collector, International Journal of Heat and Technology, Vol. 33, No. 2, pp. 17-24.

[4] Wenxian L. Optimum inclinations of south-facing solar collectors during the heating season in China. Energy 1989;14:123-9.

[5] Zhuang C., Fu B., Huang G., Zhang H. (2016). Optimization of the structure of a solar air heater fitted with V-shaped perforated baffles, International Journal of Heat and Technology, Vol. 34, No. 4, pp. 604-610.

[6] N. Bozorgan, M.Shafahi, Performance evaluation of nanofluids in solar energy: a review of the recent literature, Bozorgan and Shafahi Micro and Nano Systems Letters (2015) 3:5.

[7] S.U.S. Choi, Enhancing thermal conductivity of fluids with nanoparticles, ASME FED 231 (1995) 99-105.

[8] N. Azwadi Che Sidik et al., A review on the application of nanofluids in vehicle engine cooling system, International Communications in Heat and Mass Transfer 68 (2015) 8590.

[9] Heris SZ, Edalati Z, Noie SH, Mahian O. Experimental investigation of Al2O3/water nanofluid through equilateral triangular duct with constant wall heat flux in laminar flow. Heat Transf Eng 2014;35:1173e82.

[10] Ahadi A, Yousefi T, Saghir MZ. Double diffusive convection and thermodiffusion of fullerene-toluene nanofluid in a porous cavity. Can J Chem Eng 2013;91.

[11] Michaelides EE. Brownian movement and thermophoresis of nanoparticles in liquids. Int J Heat Mass Transf 2015;81:179e87.2014.10.019.

[12] Murshed SMS. Simultaneous measurement of thermal conductivity, thermal diffusivity, and specific heat of nanofluids. Heat Transf Eng 2012;33:722e31.

[13] Haghshenas Fard M, Esfahany MN, Talaie MR. Numerical study of convective heat transfer of nanofluids in a circular tube two-phase model versus singlephase model. Int Commun Heat Mass Transf 2010; 37:91e7.2009.08.003. 
[14] K. Khanafer, K. Vafai, M. Lightstone, Buoyancy-driven heat transfer enhancement in a two-dimensional enclosure utilizing nanofluids, Int. J. HeatMass Transf. 46 (2003) 36393653.

[15]H.F. Oztop, E. Abu-Nada, Numerical study of natural convection in partially heated rectangular enclosure filled with nanofluids, Int. J. Heat Fluid Flow 29 (2008) 1326-1336.

[16] M.M. Rahman, M.M. Billah, M. Hasanuzzaman, R. Saidur, N.A. Rahim, Heat transfer enhancement of nanofluids in a lid-driven square enclosure, Numer. Heat Transf. A 62 (2012) 973-991.

[17]E. Abu-Nada, H.F. Oztop, Effects of inclination angle on natural convection in enclosures filled with CuO-water nanofluid, Int. J. Heat Fluid Flow 30 (2009) 669-678.

[18] S.Manikandan and K. Rajan, "Newhybrid nanofluid containing encapsulated paraffin wax and sand nanoparticles in propylene glycol-water mixture: Potential heat transfer fluid for energy management," Energy Conversion andManagement, vol. 137, pp. 74-85, 2017.

[19]H.D. Koca, S.Doganay, andA. Turgut, "Thermal characteristics and performance of Agwater nanofluid: Application to natural circulation loops," Energy Conversion

[20]L. S. ShyamandG.N. Tiwari, "Analytical characteristic equation of nanofluid loaded active double slope solar still coupled with helically coiled heat exchanger," Energy Conversion and Management, vol. 135, pp. 308-326, 2017.

[21] Marina S. Astanina et al., Natural convection in a differentially heated enclosure having two adherent porous blocks saturated with a nanofluid, Eur. Phys. J. Plus (2017) 132: 509

[22] Sheikholeslami M. (2017). Influence of magnetic field on nanofluid free convection in an open porous cavity by means of lattice Boltzmann Method, Journal of Molecular Liquids, Vol. 234, pp. 364-374.

[23] Sheikholeslami M. (2017). CuO-water nanofluid free convection in a porous cavity considering Darcy law, Eur. Phys. J. Plus, Vol. 132, pp. 1-11.

[24] Yasin Varol, Hakan F. Oztop, A comparative numerical study on natural convection in inclined wavy and flat-plate solar collectors, Building and Environment 43 (2008) 15351544.

[25] R. Nasrin and M. A. Alim, Natural convective inside a correugated solar collector filled with nanofluid : effect of aspect ratio, Engineering e-Transaction (ISSN 1823-6379), Vol. 7, No.2, December 2012, pp 77-85.

[26] M.M. Rahman, S. Mojumder, S. Saha, S.Mekhilef, R. Saidur, Augmentation of natural convection heat transfer in triangular shape solar collector by utilizing water based nanofluids having a corrugated bottom wall, International Communications in Heat and Mass Transfer 50 (2014) 117-127.

[27] Nasrin R., Alim M.A., Ahmed S.R., Comparative study between 2D and 3D modeling of nanofluid filled flat plate solar collector, International Journal of Heat and Technology, Vol. 34 (2016), No. 3, pp. 604-610.

[28] Ammar Maouassi, Abdelhadi Baghidja, Said Daoud, Noureddine Zeraibi, Numerical study of nanofluid heat transfer $\mathrm{SiO} 2$ through a solar flat plate collector, International Journal of Heat and Technology, Vol. 35 (2017), No. 3, pp. 619-625.

[29] Issameddine Bacha et al., Optimal Model of Thermal Conductivity and Dynamic Viscosity for Convective Heat Transfer in a Nanofluid, Journal of Nanofluids, Volume 8, Number 1, January 2019, pp. 171-178(8).

[30]D.A.G. Bruggeman. Ann. Physics (Leipzig), 24, 636, 1935. 
[31] Brinkman, H.C, The viscosity of concentrated suspensions and solutions, J.Chem. Phys. 20, 1952, 571-581.

[32] Ching-Chang Cho et al., Natural convection and entropy generation of Al2O3-water nanofluid in an inclined wavy-wall cavity, International Journal of Heat and Mass Transfer 97 (2016) 511-520.

\section{NOMENCLATURE}

A Amplitude height of the wavy wall

$\mathrm{R}_{\mathrm{k}} \quad$ Ratio of thermal conductivities

g Gravitational acceleration, $\mathrm{m} \cdot \mathrm{s}^{-2}$

$\mathrm{R}_{\beta} \quad$ Ratio of thermal expansion coefficients

$\mathrm{x}, \mathrm{y} \quad$ Cartesian coordinates, $\mathrm{m}$

P Pressure, N.m ${ }^{-2}$

$\mathrm{P}^{*} \quad$ Dimensionless pressure

Pr Prandtl Number

$\mathrm{Nu} \quad$ Nusselt number

$\mathrm{R}_{\rho} \quad$ Density ratio [-]

$\mathrm{Ra} \quad$ Rayleigh number

$\mathrm{T} \quad$ Temperature [K]

$\mathrm{t} \quad$ Time $[\mathrm{s}]$

$\mathrm{x}^{*}, \mathrm{y}^{*} \quad$ Dimensionless coordinates, $\mathrm{m}$

$\mathrm{u}, \mathrm{v} \quad$ Components of velocity fields, $\mathrm{m} . \mathrm{s}^{-1}$

$\mathrm{R}_{\mathrm{k}} \quad$ Ratio of thermal conductivities

$\mathrm{u}^{*}, \mathrm{v}^{*} \quad$ Dimensionless velocity components, $\mathrm{m} . \mathrm{s}^{-1}$

$\mathrm{K} \quad$ Thermal conductivity, $\mathrm{W} \mathrm{m}^{-1} \cdot \mathrm{K}^{-1}$

\section{GREEK SYMBOLS}

$\alpha$

$\beta$

$\mu$

$\rho$

$\left(\rho_{C}\right)$

$\varphi$

$\psi$

$\lambda$

Thermal diffusivity, $\mathrm{m}^{2} \cdot \mathrm{s}^{-1}$

Coefficient of thermal expansion, $\mathrm{K}^{-1}$

Dynamic viscosity, $\mathrm{kg} \mathrm{m}^{-1} \cdot \mathrm{s}^{-1}$

Density, kg.m ${ }^{-3}$

Heat capacity, $\mathrm{J} \mathrm{m}^{-3} \cdot \mathrm{K}^{-1}$

Volume fraction

Stream function, $\mathrm{m}^{2} . \mathrm{s}^{-1}$

Number of waves

\section{SUBSCRIPTS}

$\mathrm{f}$

nf

$\mathrm{s}$

$\mathrm{c}$

$\mathrm{h}$

eff

$*$

$\max$

av
Fluid properties

Nanofluid properties

Solid properties

Cold wall

Hot wall

Effective

Dimensional properties

Maximum

Average 